\title{
Magnitude and associated factors of caesarean section deliveries among women who gave birth in Southwest Ethiopia: institutional-based cross-sectional study
}

Ayenew Mose ${ }^{1 *}$ (D) and Haimanot Abebe $^{2}$

\begin{abstract}
Background: Caesarean section is a life-saving comprehensive obstetric procedure of women and newborn performed during childbirth-related complications and should be universally accessible for all pregnant mothers globally. Appropriate use of caesarean section can reduce maternal and perinatal mortality. However, inappropriate use of caesarean section can negatively affect infant health, women health, and future pregnancies. The magnitude and factors associated with caesarean section delivery were not consistent and will vary between different hospitals of Ethiopia. Hence, this study aimed at assessing the magnitude and factors associated with caesarean section deliveries in Southwest Ethiopia.
\end{abstract}

Methods and Materials: An institutional-based cross-sectional study was conducted from January 1 to February 29, 2020. A systematic random sampling technique was used to select 551 study participants. A pretested, structured, and face-to-face interview was used to collect data. Data were entered into Epi-data version 4.2.0 and exported to SPSS version 23 for analysis. Bivariate and multivariate analyses were used to identify factors associated with caesarean section deliveries. $P$ values $<0.05$ result were considered as a statistically significant association.

Results: The magnitude of caesarean section deliveries was found to be $32.5 \%$ (95 \% Cl; 28.6\%-36.7 \%). Mothers resided in an urban area $[\mathrm{AOR}=2.58,(95 \% \mathrm{Cl} ; 1.66-4.01)]$, multiple pregnancies $[\mathrm{AOR}=3.15,(95 \% \mathrm{Cl} ; 1.89-5.23)$, malpresentation $[\mathrm{AOR}=3.05,(95 \% \mathrm{Cl} ; 1.77-5.24)]$, and previous history of caesarean section $[\mathrm{AOR}=3.55,(95 \% \mathrm{Cl}$; 2.23-5.64) were factors associated with caesarean section deliveries.

Conclusions: Caesarean section deliveries were found high in the study area. Mothers resided in an urban area, multiple pregnancies, malpresentation, and previous history of caesarean section were factors associated with caesarean section deliveries. Therefore, counselling of mothers on the risk of giving birth through elective caesarean section without absolute and relative medical indications and giving enough time for the trial of vaginal birth after caesarean section are recommended.

Keywords: Caesarean section, Magnitude, Associated Factors, Southwest Ethiopia

* Correspondence: ayenew8484@gmail.com

${ }^{1}$ Department of Midwifery, College of Medicine and Health Science, Wolkite University, P.O.Box; 07, Wolkite, Ethiopia

Full list of author information is available at the end of the article

C C The Author(s). 2021 Open Access This article is licensed under a Creative Commons Attribution 4.0 International License, which permits use, sharing, adaptation, distribution and reproduction in any medium or format, as long as you give appropriate credit to the original author(s) and the source, provide a link to the Creative Commons licence, and indicate if changes were made. The images or other third party material in this article are included in the article's Creative Commons licence, unless indicated otherwise in a credit line to the material. If material is not included in the article's Creative Commons licence and your intended use is not permitted by statutory regulation or exceeds the permitted use, you will need to obtain permission directly from the copyright holder. To view a copy of this licence, visit http://creativecommons.org/licenses/by/4.0/ The Creative Commons Public Domain Dedication waiver (http://creativecommons.org/publicdomain/zero/1.0/) applies to the data made available in this article, unless otherwise stated in a credit line to the data. 


\section{Background}

Caesarean section (CS) is a comprehensive obstetric lifesaving procedure of women and newborn performed during pregnancy and childbirth-related complications and should be universally accessible for all pregnant mothers globally [1]. Appropriate and timely use of CS can reduce maternal and perinatal morbidity and mortality. However, inappropriate use of caesarean section increased the risk of short-term and long-term maternal complications that can negatively affect infant health, women health, and future pregnancies $[1,2]$. Currently, caesarean section is rising at an alarming rate, often for non-medical indications, has become a major public health concern globally [3].

A systemic review and meta-analysis conducted by Sobhy S, et al., showed that the risk of women dying after caesarean sections in developing countries was a hundred times higher than in developed countries. The burden was higher in Sub-Saharan Africa indicated that 1 out of 100 women died after CS, 82.5 stillbirths, and 100.4 perinatal deaths per 1000 caesarean sections have occurred [4]. Unnecessary use of CS without medical indication and lack of quality obstetric health care service after surgery were the major reasons for women death, stillbirth, and perinatal death $[4,5]$. In 2015, the World Health Organization (WHO), suggested CS should be performed only when it is medically necessary, and more than $10-15 \%$ of CS rates have not shown any potential benefits in the reduction of maternal and neonatal mortality [6].

The magnitude of caesarean section was varied across different countries. For instance, studies done in Latin American and Caribbean regions $40.5 \%$ [2], United states $32 \%$ [7], South Africa 42.4\% [8], South India $32.6 \%$ [9], Tanzania $27 \%$ [10], Sri Lanka 25.13\% [11], United Arab Emirates 30.2\% [12], Bangladesh $13 \%$ [13], and in Ethiopia between 20.2 and $38.3 \%$ of mothers were undergone caesarean section [14-20].

The most commonly cited factors of performing caesarean section were antepartum haemorrhage, fetal macrosomia, previous history of caesarean section, urban residence, and abnormal presentation were reported [13, 15-19]. Failed induction of labour, nonreassuring fetal heart rate pattern, and failure of labour progress were reported indications of performing caesarean section $[8,15,18,21]$.

The factors associated with caesarean section are multifactorial, complex, and will vary between different hospitals of Ethiopia. Besides, most of the abovepublished studies were conducted in a single hospital, used secondary data might affect by incomplete /missing files. Additionally, they were lack assessing the leading indications of caesarean section. Moreover, there was limited information regarding the magnitude and factors associated with caesarean section in the study area. Hence, this study aimed at assessing the magnitude, leading indications, and factors associated with caesarean section deliveries in Southwest Ethiopia. This study will have paramount importance for hospitals, zonal health offices, and policymakers to upgrade quality maternal and neonatal obstetric health care services provision.

\section{Methods and materials}

\section{Study area, design and period}

An institutional-based cross-sectional study was conducted from January 1 to February 29 in Gurage zone hospitals, Southwest Ethiopia. According to the 2011 census conducted by the Central Statistical Agency of Ethiopia (CSA) report, the zone has a total population of $8,556,964$, of whom $4,278,482$ are men and 3,422,785.6 women. In the near future, the total population of Gurage zone was projected to 6.5 million [20]. Gurage zone is located $187 \mathrm{~km}$ southwest of Addis Ababa the capital city of Ethiopia. Gurage zone has a total of 5 hospitals, 72 health centres, and 402 health posts that provides maternal and neonatal health care services for the catchment population. All 5 hospitals were providing comprehensive obstetric health care service and included in this study. Antenatal care, delivery, and postnatal care service were provided free of charge in the study area.

\section{Population and sampling}

All mothers who gave birth in Gurage zone hospitals were considered as the source population and mothers who were selected using systematic random sampling technique during the study period were considered as the study population. All mothers who gave birth in Gurage zone hospitals were included. Mothers who had critically ill, develop a childbirth complication, and unable to respond during data collection period were excluded. Single population proportion formula was used to calculate the final sample size. The following assumptions were considered; $p=30.9 \%$, the proportion of mothers who had given birth through caesarean section in North Wollo Zone public hospitals, Amhara region, Northeast Ethiopia [17], $95 \%$ confidence interval $(\mathrm{Z \alpha} /$ $2=1.96), 4 \%$ margin of error $(d=0.04)$, and $10 \%$ nonrespondent rate. Therefore, the final sample size was calculated to be 551. After reviewing two months of the obstetric case follow of all five hospitals, the final sample size was allocated to each hospital proportionally. Finally, the study subjects were selected using a systematic random sampling method based on the client flow in each hospital until reaching the final sample size.

\section{Study variables and measurements}

The main outcome variable in this study was caesarean section delivery. Caesarean section (C-section) is defined 
as a comprehensive obstetric surgical incision in a women's abdomen and uterus for delivery of the fetus, membrane, and placenta after viability of the fetus. Those mothers who had given birth through vaginal delivery includes instrumental deliveries (i.e. forceps and vacuum delivery) were coded as ' 1 ' and those mothers who had given birth via CS coded as '0' [17].

The explanatory variables for this study were includes; gravidity, categorized as 'primigravida', 'multigravida' and 'grand multigravida'; parity, categorized as 'nulliparous' or 'multipara', 'Grand multiparous'; fetal lie/presentation, categorized as 'breech' or 'cephalic', lie 'transverse or oblique'; onset of labour, categorized as 'spontaneous', 'induced or CS before labour'; malpresentation, categorized as 'Yes' and 'No'; multiple pregnancies, categorized as 'singleton' or 'multiple'; Gestational age, classified as 'term $>37$ weeks', 'preterm < 37 weeks' and 'post-term > 42 weeks' new-born birth weight; newborn birth weight, categorized as 'normal birth weight (2500-4000gm)', 'low birth weight (<2500gm)', 'macrosomia (> 4000gm)'; previous history of CS, categorized as 'Yes' and 'No'[22, 23].

\section{Data collection tool and procedures}

The tool was adapted after reviewing different relevant literatures [15-17, 24-29]. Firstly, the questionnaire was prepared in 'English language' and translated to 'Amharic language' by Amharic language experts and then translated backs to the 'English language' to check its consistency. The tool contains three parts; part 1, socio-demographic characteristics; part 2, obstetric related variables; and part 3 , indications of performing caesarean section. Data were collected through reviewing of medical records of mothers and a structured, face-toface exit interview was used. Five midwives (BSc) and one MSc health professionals participated in the data collections and supervision respectively. All relevant information including socio-demographic characteristics, obstetric related variables, and indications of performing caesarean section were collected.

\section{Data quality assurance}

To ensure data quality, two days of training (one day for theoretical and one day for practical) were given for both data collectors and supervisor by principal investigator on the technique of the data collection process. A pretest was done on $5 \%$ of the sample size before data collection was processed and some modifications were done. The principal investigator and supervisor were closely follow-up the data collection process.

\section{Data processing and analysis}

Data was clean, coded, and entered into Epi-data version 4.2.0 and exported into SPSS version 23 for further analysis. The magnitude of caesarean section was analysed.
Data were presented in the form of frequency, mean, standard deviation, tables, pie-chart, and figures. Bivariate and multivariate analysis was done using the binary logistic regression model to identify factors associated with caesarean section deliveries. All statistically significant variables in bivariate logistic regression model were taken into account for multicollinearity tests. Multicollinearity test was carried out using Variance Inflation Factor (VIF). Thus, the result of multi-collinearity test showed that there is no evidence of collinearity among the independent variables, since all included variables had $\mathrm{VIF}<10$. Hosmer-Lemeshow goodness tests were carried out to check model fitness (0.85). $P$-value $<0.05$ results along with adjusted odd ratio $95 \%$ confidence interval was used to declare a result as a statistically significant association.

\section{Results}

\section{Socio-demographic characteristics}

A total of 551 women were participated in this study and making a response rate of $98 \%$. The mean age of the respondents was $27.33( \pm 4.83)$ years. Among a total study participants, $336(61 \%)$ were found in the age group between 25 and 34 years. Regarding maternal educational status, 211 (38\%) of mothers have completed primary education. Concerning marital status, 486 (88\%) women were married. Regarding residence, 400 (73\%) of study participants were lived in rural areas and $402(73 \%)$ of respondents were Gurage ethnicity. Concerning religion, 349 (63\%) of study participants were orthodox religious followers (Table 1).

\section{Obstetric related characteristics}

The finding of this study showed that, 334 (61\%) and $402(73 \%)$ of mothers were multigravida and multiparous respectively. Out of the total respondents, 366 $(66 \%)$ of mothers had antenatal care visits and 211 (38\%) of mothers were utilized antenatal care services more than four times. About 302 (55\%) of mothers had practiced an antenatal care group. About 432 (78\%) of mothers had normal cephalic presentation and 415 (75\%) of mothers had experienced spontaneous onset of labour. Regarding gestational age and neonatal birth weight, 413 (75\%) of mothers gave birth at term (37-42 week) and $410(74 \%)$ of mothers had normal birth weight newborn (2500-400gm). Concerning the previous history of caesarean section, 69 (13\%) of mothers had history of previous caesarean section (Table 2).

\section{Indication for performing caesarean section}

This study found that previous history of caesarean section 48 (27\%), and obstructed labour 28 (16\%) were the relative and absolute indications of performing CS respectively (Fig. 1). 
Table 1 Socio-demographic characteristics of women's who gave birth in Southwest Ethiopia, 2020

\begin{tabular}{|c|c|c|}
\hline Variable & Frequency & Percentage \\
\hline \multicolumn{3}{|l|}{ Maternal age } \\
\hline $15-24$ & 152 & 28 \\
\hline $25-34$ & 336 & 61 \\
\hline $35-44$ & 63 & 11 \\
\hline \multicolumn{3}{|l|}{ Marital status } \\
\hline Single & 21 & 4 \\
\hline Married & 486 & 88 \\
\hline Divorced/widowed & 44 & 8 \\
\hline \multicolumn{3}{|l|}{ Maternal educational status } \\
\hline No formal education & 192 & 35 \\
\hline Primary education & 211 & 38 \\
\hline Secondary education and above & 148 & 27 \\
\hline \multicolumn{3}{|l|}{ Residence } \\
\hline Urban & 151 & 27 \\
\hline Rural & 400 & 73 \\
\hline \multicolumn{3}{|l|}{ Maternal occupation } \\
\hline Housewife & 357 & 65 \\
\hline Merchant & 77 & 14 \\
\hline Government employee & 103 & 19 \\
\hline Daily labourer & 14 & 3 \\
\hline \multicolumn{3}{|l|}{ Religion } \\
\hline Orthodox & 349 & 63 \\
\hline Muslim & 157 & 29 \\
\hline Protestant & 45 & 8 \\
\hline \multicolumn{3}{|l|}{ Ethnicity } \\
\hline Gurage & 402 & 73 \\
\hline Amhara & 115 & 21 \\
\hline Oromo & 34 & 6 \\
\hline
\end{tabular}

The magnitude of caesarean section

Out of the magnitude of caesarean section surgery $32.5 \%, 10.5 \%$, and $21.9 \%$ of mothers were given birth through elective and emergency caesarean sections respectively, while the magnitude of vaginal delivery was found to be $67.5 \%$ (Fig. 2).

\section{Factors associated with caesarean section deliveries}

The bivariate and multivariate logistic regression analysis model was done to identify factors associated with caesarean section delivery. In binary logistic regression model mothers resided in an urban area, multiple pregnancies, newborn low birth weight $(<2,5000 \mathrm{gm})$, malpresentation, and previous history of caesarean section were significantly associated with caesarean section delivery.
Table 2 Obstetric related characteristics of women's who gave birth in Southwest Ethiopia, 2020

\begin{tabular}{|c|c|c|}
\hline Variables & Frequency & Percentage $/ \% /$ \\
\hline \multicolumn{3}{|l|}{ Gravidity } \\
\hline Primigravida & 92 & 17 \\
\hline Multigravida & 334 & 61 \\
\hline Grand multigravida & 125 & 23 \\
\hline \multicolumn{3}{|l|}{ Parity } \\
\hline Primiparaous & 82 & 15 \\
\hline Multiparaous & 402 & 73 \\
\hline Grand multiparous & 67 & 12 \\
\hline \multicolumn{3}{|l|}{ ANC visit } \\
\hline Yes & 366 & 66 \\
\hline No & 185 & 34 \\
\hline \multicolumn{3}{|l|}{ Number of ANC visits } \\
\hline 1 & 55 & 10 \\
\hline 2 & 44 & 8 \\
\hline 3 & 56 & 10 \\
\hline$\geq 4$ & 211 & 38 \\
\hline \multicolumn{3}{|l|}{ Participation in antenatal care group } \\
\hline Yes & 302 & 55 \\
\hline No & 249 & 45 \\
\hline \multicolumn{3}{|l|}{ Fetal presentation /lie } \\
\hline Breech & 72 & 13 \\
\hline Cephalic & 432 & 78 \\
\hline Transverse/oblique & 47 & 9 \\
\hline \multicolumn{3}{|l|}{ Onset of labour } \\
\hline Spontaneous & 415 & 75 \\
\hline Induced & 78 & 14 \\
\hline No labour (pre-labour CS) & 58 & 11 \\
\hline \multicolumn{3}{|l|}{ Multiple pregnancy } \\
\hline Yes & 96 & 17 \\
\hline No & 455 & 83 \\
\hline \multicolumn{3}{|l|}{ Gestational age } \\
\hline Term (37-42 week) & 413 & 75 \\
\hline Preterm (<37 week) & 71 & 13 \\
\hline Post term (> 42 week) & 67 & 12 \\
\hline \multicolumn{3}{|l|}{ Malpresentation } \\
\hline Yes & 129 & 23 \\
\hline No & 422 & 77 \\
\hline \multicolumn{3}{|l|}{ Newborn birth weight } \\
\hline Normal birth weight (2500-4000gm) & 410 & 74 \\
\hline Low birth weight (<2500gm) & 78 & 14 \\
\hline Macrosomia (> 4000gm) & 63 & 12 \\
\hline \multicolumn{3}{|l|}{ Previous history of caesarean section } \\
\hline Yes & 69 & 13 \\
\hline No & 482 & 87 \\
\hline
\end{tabular}




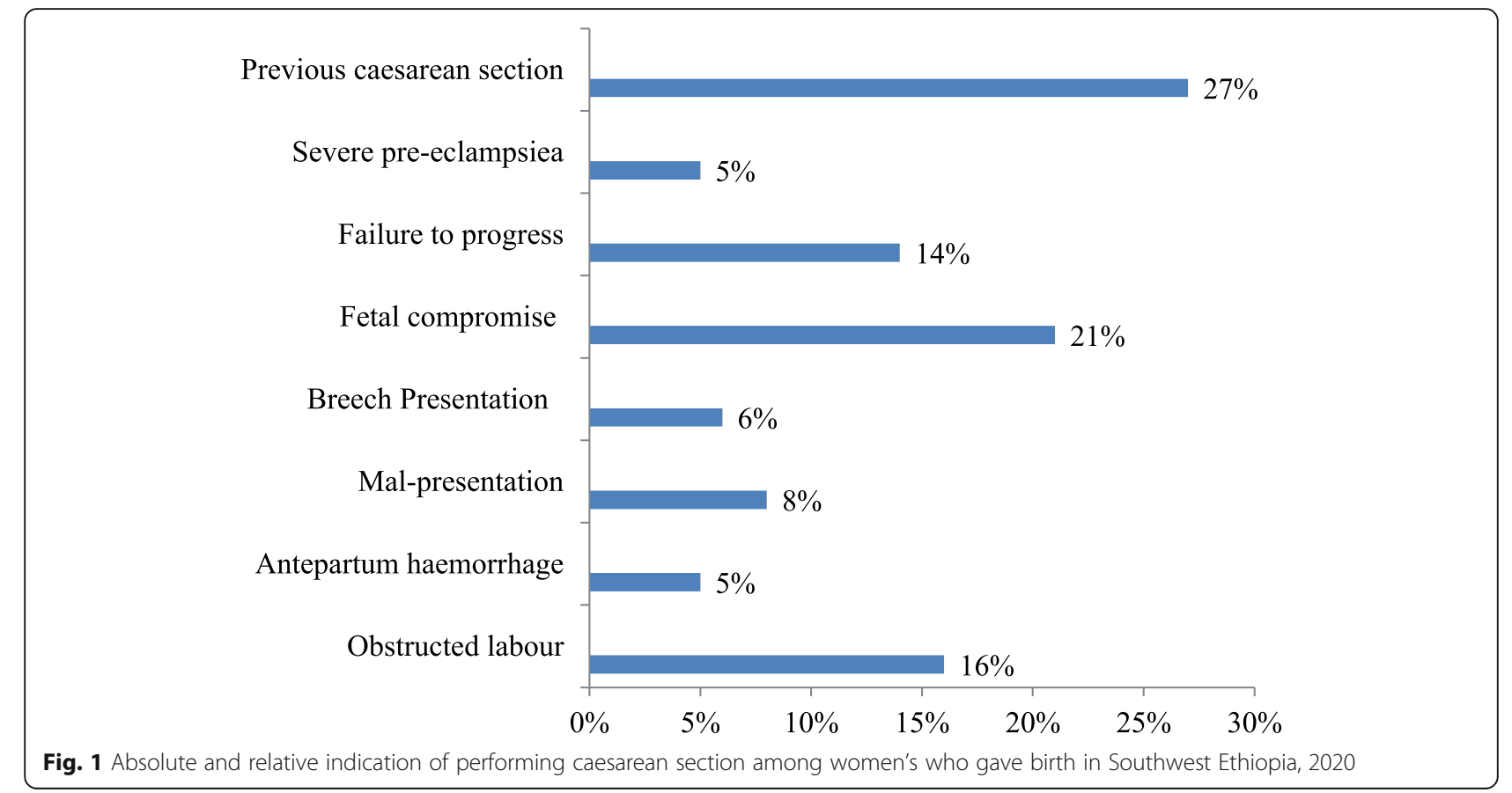

In the multivariate binary logistic regression model analysis after controlling the confounders; mothers resided in an urban area, multiple pregnancies, malpresentation, and previous history of caesarean section were significantly associated with caesarean section delivery. Postpartum mothers who lived in urban areas were 2.58 times more likely to give birth through caesarean section delivery than those mothers who had lived in rural areas $[\mathrm{AOR}=2.58$, (95\% CI:1.66-4.02)]. Postpartum mothers who had been diagnosed with multiple pregnancies were 2 times more likely to give birth through caesarean section compared to those mothers who had single tone pregnancies [AOR = 2.15, (95\% CI:1.89-5.23)]. Postpartum mothers who had been diagnosed with malpresentation were 3 times more likely to give birth through caesarean section than their counterparts $[\mathrm{AOR}=3.05$, (95\% CI: 1.77-5.24)]. Postpartum mothers who had previous history of caesarean section were 2.5 times more likely to give birth through caesarean section than those women who did not have a history of previous CS $[\mathrm{AOR}=2.55,(95 \% \mathrm{CI}: 2.23-5.64)]$ (Table 3).

\section{Mode of Delivery}

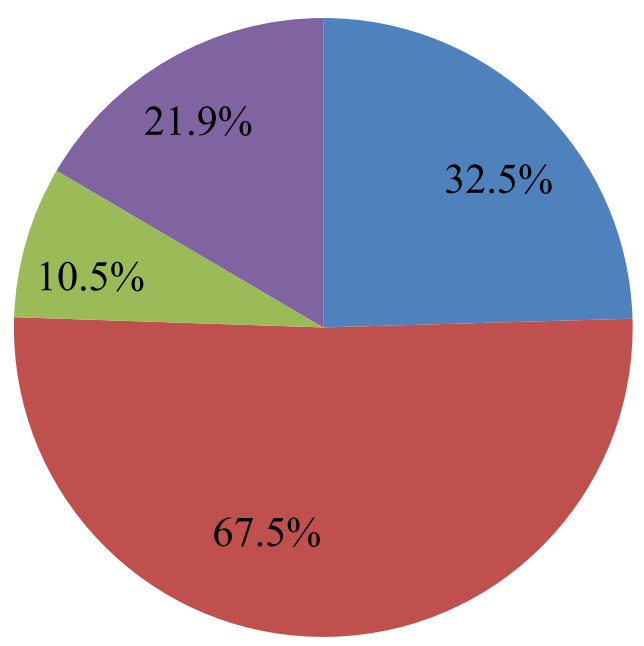

Caesarean section

Vaginal delivery

Elective caesarean section

Emergency caesarean section

Fig. 2 Magnitude of caesarean section delivery among women who gave birth in in Southwest Ethiopia, 2020 
Table 3 Bivariate and multivariate logistic regression to identify determinate factors of caesarean section delivery among women's who gave birth in Southwest Ethiopia, 2020

\begin{tabular}{|c|c|c|c|c|}
\hline \multirow[t]{2}{*}{ Variables } & \multicolumn{2}{|c|}{ Caesarean Section Delivery } & \multirow[t]{2}{*}{ COR $(95 \% \mathrm{Cl})$} & \multirow[t]{2}{*}{ AOR $(95 \% \mathrm{Cl})$} \\
\hline & No (\%) & Yes (\%) & & \\
\hline \multicolumn{5}{|l|}{ Maternal age } \\
\hline $15-24$ & 102(19) & $50(9)$ & $0.82(0.43-1.55)$ & $1.15(0.54-2.46)$ \\
\hline $25-34$ & $225(41)$ & $111(20)$ & $0.81(0.45-1.47)$ & $1.03(0.52-2.05)$ \\
\hline $35-44$ & $45(8)$ & $18(3)$ & 1 & 1 \\
\hline \multicolumn{5}{|l|}{ Maternal educational status } \\
\hline No formal education & $135(25)$ & $57(10)$ & 1 & 1 \\
\hline Primary education & $140(25)$ & $71(13)$ & $0.8(0.79-1.97)$ & $1.1(0.62-1.91)$ \\
\hline Secondary and above & $97(18)$ & $51(9)$ & $0.8(0.67-1.62)$ & $0.9(0.53-1.54)$ \\
\hline \multicolumn{5}{|l|}{ Place of residence } \\
\hline Rural & 298(54) & 102(19) & 1 & 1 \\
\hline Urban & $74(13)$ & $77(14)$ & $3.04(2.06-4.49)^{*}$ & $2.58(1.66-4.02)^{*}$ \\
\hline \multicolumn{5}{|l|}{ Gravidity } \\
\hline Primigravida & $59(11)$ & $33(6)$ & $0.72(0.41-1.29)$ & $0.717(0.37-1.38)$ \\
\hline Multigravida & $224(41)$ & $110(20)$ & $0.82(0.53-1.29)$ & $0.81(0.48-1.35)$ \\
\hline Grand multigravida & $89((16)$ & $36(7)$ & 1 & 1 \\
\hline \multicolumn{5}{|l|}{ Parity } \\
\hline Primiparaous & $28(5)$ & $54(10)$ & $0.37(0.41-1.29)$ & $0.72(0.37-1.38)$ \\
\hline Multiparous & $305(55)$ & $97(18)$ & $2.26(0.53-2.91)$ & $2.81(0.68-3.35)$ \\
\hline Grand multiparous & $39(7)$ & $28(5)$ & 1 & 1 \\
\hline \multicolumn{5}{|l|}{ ANC visit } \\
\hline Yes & 239(43) & $127(23)$ & $0.74(0.5-1.08)$ & $0.69(0.44-1.08)$ \\
\hline No & 133(24) & $52(9)$ & 1 & \\
\hline \multicolumn{5}{|l|}{ Multiple pregnancy } \\
\hline Yes & $71(13)$ & $25(5)$ & $1.45(1.27-5.64)^{*}$ & $2.15(1.89-5.23)^{*}$ \\
\hline No & $301(55)$ & 154(28) & 1 & 1 \\
\hline \multicolumn{5}{|l|}{ Gestational age } \\
\hline Term(37-42 week) & $287(52)$ & $126(23)$ & 1 & 1 \\
\hline Preterm(<37 week) & $45(8)$ & $26(5)$ & $0.76(0.78-1.23)$ & 0.89(0.38-2.09) \\
\hline Post term(>42 week) & $40(7)$ & $27(5)$ & $0.65(0.431-1.701)$ & $1.087(0.57-2.08)$ \\
\hline \multicolumn{5}{|l|}{ Malpresentation } \\
\hline Yes & 101(18) & $28(5)$ & $2.01(1.96-4.99)^{*}$ & $3.05(1.77-5.24)^{*}$ \\
\hline No & 271(49) & $151(27)$ & 1 & 1 \\
\hline \multicolumn{5}{|l|}{ Newborn birth weight } \\
\hline Normal birth weight & $278(51)$ & 132(24) & 1 & 1 \\
\hline Low birth weight & $56(10)$ & $22(4)$ & $1.21(1.01-1.41)^{*}$ & $0.98(0.54-1.77)$ \\
\hline Macrosomia & $38(7)$ & $25(5)$ & $0.72(0.29-1.21)$ & $0.55(0.25-1.21)$ \\
\hline \multicolumn{5}{|l|}{ Pervious history of CS } \\
\hline Yes & $48(9)$ & $21(4)$ & $1.11(1.001-1.9)^{*}$ & $2.55(2.23-5.64)^{*}$ \\
\hline No & $324(59)$ & 158(29) & 1 & 1 \\
\hline
\end{tabular}

${ }^{*} p$ value $<0.05,1=$ ref., Hosmer-Lemeshow goodness tests $=0.85$ 


\section{Discussion}

Caesarean section is a life-saving comprehensive obstetric procedure for women and newborn performed during pregnancy and childbirth-related complications [6]. However, inappropriate use of caesarean section can negatively affect women health [5]. This study found that a significant proportion of mothers were giving birth through caesarean section. The multivariate analysis shows that mothers resided in urban areas, multiple pregnancies, malpresentation, and previous history of caesarean section were significantly associated with caesarean section deliveries.

The present study revealed that the magnitude of CS was found to be $32.5 \%$ indicated that almost twice more than the WHO recommendation of $10-15 \%$ [6]. The finding was slightly higher than studies conducted in Felegehiwot referral hospital, Amhara region, Northwest Ethiopia 25.4\% [16], Nepal 22.6\% [23], Vietnam 26.2 \%, [26], Sri Lanka, India $25 \%$ [11], Mizan-Aman general hospital, Southwest Ethiopia 21\% [25] and Shire, Tigray region, Northern Ethiopia 20.2\% [15]. The result was nearly consistent with studies conducted in North Wollo Zone public hospitals, Amhara region, Northeast Ethiopia $30.9 \%$ [17], Hawassa university referral hospital, southern Ethiopia $32.8 \%$ [18], and Jugal hospital, Harari Regional State, eastern Ethiopia 29.7 \% [28]. However, it was lower than studies conducted in Addis Ababa public hospitals $38.3 \%$ [14], Tanzania $49 \%$ [10], and South Africa $42.4 \%$ [8]. The possible explanation for the difference might be due to variation in socio-demographic characteristics of women, sample size determination, geographical location, and access to comprehensive obstetric health care services.

Postpartum mothers who had lived in urban areas were 2.58 times more likely to give birth through caesarean section than those mothers who had lived in rural areas. The result was consistent with a study conducted in North Wollo Zone public hospitals, Amhara region, Northeast Ethiopia [17], and Vietnam [26]. The reason might be those mothers who had lived in urban areas have better access to comprehensive obstetric health care service and they do have awareness of the long duration of labour pain. Therefore, due to fear of labour pain pregnant mothers might prefer to give birth through caesarean section compared to spontaneous vaginal delivery. However, the finding was inconsistent with a study conducted in Felegehiwot Referral Hospital, Amhara region, Northwest Ethiopia [16]. In Felegehiwot referral hospital those mothers who had resided in rural areas were more likely to give birth through caesarean section than those who had resided in urban areas. The possible explanation might be due to the difference in ANC service utilization. For instance, those mothers who lived in rural areas might have delayed initiation of
ANC service, low healthcare seeking behaviours, and delayed decision making process, which might increase the risk of obstetric complication and in turn, increase the probability of giving birth through caesarean section.

Postpartum mothers who had been diagnosed with multiple pregnancies were nearly 2 times more likely to give birth through caesarean section compared to those mothers who had diagnosed with single-tone pregnancies. The possible explanation might be multiple pregnancies were associated with obstetric complications such as preterm labour, the premature rupture of membranes, malposition, and malpresentation of the fetus might increase the probability of giving birth through caesarean section. Additionally, health care workers might decide to perform caesarean section to avoid the risk of maternal and neonatal mortality associated with multiple pregnancies.

Postpartum mothers who had been diagnosed with malpresentation were 3 times more likely to give birth through caesarean section compared to their counterparts. The finding was in line with other studies conducted in Felegehiwot referral hospital, Amhara region, Northwest Ethiopia and North Wollo Zone public hospitals, Amhara region, Northeast Ethiopia [16, 17]. The reason could be due to the fact that malpresentation might be associated with prolonged labour, fetal distress, cephalopelvic disproportion, which might affects the progress of normal labour and in turn, physicians might prefer to perform caesarean section to increase the chance of maternal and neonatal survival.

Postpartum mothers who had a previous history of caesarean section were 2.5 times more likely to give birth through caesarean section compared to those mothers who did not have a previous history of caesarean section. The finding was comparable with a study conducted in North Wollo Zone public hospitals, Amhara region, Northeast Ethiopia [17], and Addis Ababa public hospitals [14]. The possible justification might be due to those women who had a history of previous caesarean section might develop antepartum haemorrhage, might have bad obstetric history, medical and surgical problems that compromise the effort or attempt of a trial of vaginal birth after caesarean section.

Our study also assessed the main indications of performing caesarean section. Thus, having previous history of caesarean section, fetal compromise, obstructed labour, and failure of labour progress was the leading indication of performing caesarean section. The finding was comparable with other studies conducted in Hawassa referral hospital, Eastern Ethiopia, Nepal, and South Africa [8, 18, 24]. The possible justification might be the fact that most of the leading indications of performing caesarean section listed in the above were medically acceptable reasons. For instance, those mothers 
who had previous history of caesarean section is a relative indication for caesarean section due to the risk of uterine ruptures. Fetal compromise, obstructed labour, and failure of labour progress were also an indication for caesarean section, because continuing spontaneous vaginal delivery might increase the risk of stillbirth and maternal mortality.

In general, maternal and neonatal mortality can be averted using medically justifiable caesarean section procedure. The predominant factors associated with caesarean section deliveries were identified such as mother resided in an urban area, multiple pregnancies, malpresentation, and previous history of caesarean section. This study has several strengths such as identifying leading indications and factors associated with caesarean section delivery in the study area and it used prospective data that in turn minimizes missing/incomplete data. However, this study was not void of limitations; for instance, lack of including health care provider perspective regarding the rising rate of caesarean section deliveries and it also shares limitation of cross-sectional study design.

\section{Conclusion}

The overall magnitude of caesarean section was found high in the study area. Mothers resided in an urban area; multiple pregnancies, malpresentation, and previous history of caesarean section were significantly associated with caesarean section deliveries. Therefore, counselling of mothers on the risk of giving birth through caesarean section without absolute and relative medical indications and giving enough time particularly for those women who underwent a trial of vaginal birth after caesarean section is recommended.

\section{Abbreviations}

ANC: Antenatal care; CS: Caesarean Section; APH: Antepartum Haemorrhage; SPSS: Statistical Package for Social Sciences; WHO: World Health Organizations

\section{Acknowledgements}

We would like to thank Wolkite University, data collectors, and supervisor for their effort to accomplish this research.

\section{Authors' contributions}

AM wrote the proposal and undertook statistical analysis. AM and HA contributed to the writing of the manuscript and both authors approved the submitted version of the manuscript.

\section{Funding}

Not applicable.

\section{Availability of data and materials}

The data set used for this research is not available online. However, it is available upon reasonable request from the corresponding author.

\section{Declarations}

Ethics approval and consent to participate

Ethical approval was obtained from Wolkite University, College of Medicine and Health Science Ethical Review Committee with Ref, no (CMHS/12/2020) An official letter was written to the Gurage zone health office. Then, a cooperation letter was written to Gurage zone public hospitals. The study purpose and objective were briefly explained for each study participant and informed written consent was taken. In the case of mothers who are unable to read or write thumbprint was taken. The right to not participate or withdraw fully or partially from this study during the data collection period was fully provided to the study participants.

\section{Consent for publication}

Not applicable.

\section{Competing interests}

The authors declare that they have no competing interests.

\section{Author details}

'Department of Midwifery, College of Medicine and Health Science, Wolkite University, P.O.Box; 07, Wolkite, Ethiopia. ${ }^{2}$ Department of Public Health, College of Medicine and Health Science, Wolkite University, Wolkite, Ethiopia.

Received: 20 April 2021 Accepted: 23 August 2021

Published online: 02 September 2021

\section{References}

1. Sandall J, Tribe RM, Avery L, Mola G, Visser GH, Homer CS, et al. Short-term and long-term effects of caesarean section on the health of women and children. Lancet. 2018:392(10155):1349-57.

2. Betrán AP, Ye J, Moller AB, Zhang J, Gülmezoglu AM, Torloni MR. The increasing trend in caesarean section rates: Global, regional and national estimates: 1990-2014. PLoS One. 2016;11(2):1-12.

3. Vega ES. Rising Trends of cesarean section worldwide: a systematic review. Obstet Gynecol Int J. 2015;3(2):00073.

4. Sobhy S, Arroyo-Manzano D, Murugesu N, Karthikeyan G, Kumar V, Kaur I, et al. Maternal and perinatal mortality and complications associated with caesarean section in low-income and middle-income countries: a systematic review and meta-analysis. Lancet. 2019;393(10184):1973-82. https://doi.org/1 0.1016/50140-6736(18)32386-9.

5. Souza JP, Gülmezoglu AM, Lumbiganon P, Laopaiboon M, Carroli G, Fawole $B$, et al. Caesarean section without medical indications is associated with an increased risk of adverse short-term maternal outcomes: The 2004-2008 WHO Global Survey on Maternal and Perinatal Health. BMC Med. 2010;8(1): 71. Available from: http://www.biomedcentral.com/1741-7015/8/71.

6. Wagman H. Caesarean section rates. Lancet. 1993;342(8885):1490.

7. Martin JA, Hamilton BE, Osterman MJ, Driscoll AK, Matthews TJ. National vital statistics reports. Natl Vital Stat Rep. 2017;66(1):1-70. Available from: http:// www.cdc.gov/nchs/data_access/vitalstatsonline.htm\%0Ahttp://www.cdc.gov/ nchs/VitalStats.htm\%0Ahttps://www.cdc.gov/nchs/data/nvsr/nvsr66/nvsr66_01. pdf\%0Apapers3://publication/uuid/277FA8C2-3AA6-4435-8282-DEA7F3E78FE1.

8. Makhanya V, Govender L, Moodley J. Utility of the Robson ten group classification system to determine appropriateness of caesarean section at a rural regional hospital in KwaZulu-Natal, South Africa. South Afr Med J. 2015, 105(4):292-5.

9. Dhodapkar S, Bhairavi S, Daniel M, Chauhan N, Chauhan R. Analysis of caesarean sections according to Robson's ten group classification system at a tertiary care teaching hospital in South India. Int J Reprod Contraception Obstet Gynecol. 2015;4:745-9.

10. Litorp H, Kidanto HL, Nystrom L, Darj E, Essén B. Increasing caesarean section rates among low-risk groups: A panel study classifying deliveries according to Robson at a university hospital in Tanzania. BMC Pregnancy Childbirth. 2013:13:1-10.

11. Yingwani-Mlambo L, Mabenge M, Phil M. Analysis of caesarean sections using Robson 10-group classification system in a tertiary hospital, Port Elizabeth. Obstet Gynaecol Forum. 2020;30(2):23-6.

12. Taha Z, Hassan AA, Wikkeling-Scott L, Papandreou D. Prevalence and associated factors of caesarean section and its impact on early initiation of breastfeeding in Abu Dhabi, United Arab Emirates. Nutrients. 2019;11(11): 2723 
13. Karim F, Ali NB, Khan ANS, Hassan A, Hasan MM, Hoque DME, et al. Prevalence and factors associated with caesarean section in four hard-toreach areas of Bangladesh: Findings from a cross-sectional survey. PLoS One. 2020;15(6):1-16. https://doi.org/10.1371/journal.pone.0234249.

14. Tsegaye H, Desalegne B, Wassihun B, Bante A, Fikadu K, Debalkie M, et al. Prevalence and associated factors of caesarean section in Addis Ababa hospitals, Ethiopia. Pan Afr Med J. 2019;34:1-9.

15. Alemu AA, Zeleke LB. Magnitude and Determinants of Primary Cesarean Section Among Women Who Gave Birth in Shire, Northern Ethiopia. Open Access Surg. 2020;13:53-9.

16. Abebe FE, Gebeyehu AW, Kidane AN, Eyassu GA. Factors leading to cesarean section delivery at Felegehiwot referral hospital, Northwest Ethiopia: a retrospective record review. Reprod Health. 2016;13:1-7. https:// doi.org/10.1186/s12978-015-0114-8.

17. Ayalew M, Mengistie B, Dheressa M, Demis A. Magnitude of cesarean section delivery and its associated factors among mothers who gave birth at public hospitals in Northern Ethiopia: Institution-based cross-sectional study. J Multidiscip Healthc. 2020;13:1563-71.

18. Abdo AA, Hinderaker SG, Tekle AG, Lindtjørn B. Caesarean section rates analysed using Robson's 10-Group Classification System: a cross-sectional study at a tertiary hospital in Ethiopia. BMJ Open. 2020;10(10):1-8.

19. Abubeker FA, Gashawbeza B, Gebre TM, Wondafrash M, Teklu AM, Degu D, et al. Analysis of cesarean section rates using Robson ten group classification system in a tertiary teaching hospital, Addis Ababa, Ethiopia: a cross-sectional study. BMC Pregnancy Childbirth. 2020;20(1):1-7.

20. gurage population 2020. Available from: https://www.cleanmaker.se/ d0klfoc1/gurage-population-2020.

21. American College of Obstetricians and Gynecologists. FAQ: Cesarean birth (C-section). 2015. Available from: https:/www.acog.org/en/WomensHealth/ FAQs/CesareanBirth. [cited 1 Feb 2020]

22. Tura AK, Pijpers O, De Man M, Cleveringa M, Koopmans I, Gure T, et al. Analysis of caesarean sections using Robson 10-group classification system in a university hospital in eastern Ethiopia: a cross-sectional study. BMJ Open. 2018;8(4):1-8.

23. Malla RV, Hamal C, Neupane B, Khatri R. Analysis of Cesarean Section Using Robson's 10-Group Classification at a Tertiary Level Hospital in Nepal. Med J Shree Birendra Hosp. 2018;17(2):4-11.

24. Cynthia, Stanton, Carine Stanton BG on C. Recommendations for Routine Reporting on Indications for Cesarean Delivery in Developing Countries. 2008;35(3):2008. doi: https://doi.org/10.1111/j.1523-536X.2008.00241.x.

25. Gutema H. Caesarean Section and Associated Factors at Mizan Aman General Hospital Southwest Ethiopia. J Gynecol Obstet. 2014;2(3):37.

26. de Loenzien M, Schantz C, Luu BN, Dumont A. Magnitude and correlates of caesarean section in urban and rural areas: a multivariate study in Vietnam. PLoS One. 2019;14(7):e0213129

27. EDHS: Ethiopia Demographic and Health Survey. Central Statistical Agency Addis Ababa, Ethiopia. 2016; Available from: https://dhsprogram.com/pubs/ pdf/FR328/FR328.pdf.

28. Jamie AH. Prevalence and Indication and Outcome of Cesarean Section in Jugal Hospital, Harari Regional State, Ethiopia, 2019: a Retrospective Study. Public Heal Indones. 2019;5(4):85-90.

29. Gebreegziabher Hailu A, Kebede Fanta T, Tekulu Welay F, Etsay Assefa N, Aregawi Hadera S, Aregawi Gebremeskel G, et al. Determinants of Cesarean Section Deliveries in Public Hospitals of Addis Ababa, Ethiopia, 2018/19: A Case-Control Study. Obstet Gynecol Int. 2020;2020:e0213129.

\section{Publisher's Note}

Springer Nature remains neutral with regard to jurisdictional claims in published maps and institutional affiliations.

Ready to submit your research? Choose BMC and benefit from:

- fast, convenient online submission

- thorough peer review by experienced researchers in your field

- rapid publication on acceptance

- support for research data, including large and complex data types

- gold Open Access which fosters wider collaboration and increased citations

- maximum visibility for your research: over $100 \mathrm{M}$ website views per year

At BMC, research is always in progress.

Learn more biomedcentral.com/submissions 